\title{
CRISIS SISTÉMICA, PROBLEMA "TECNOLÓGICO" Y DEL SUBSIGUIENTE SUBDESARROLLO EN LA ESFERA DE LA PRODUCCIÓN COMO A LA DE LA CIRCULACIÓN
}

\author{
Luciano Vasapollo \\ Profesor de Metodi di Analisi dei Sistemi Economici, y de Politica Economica en "Sapienza" Universidad de \\ Roma. Delegado del Rector para las Relaciones Internacionales con los Paises de America Latina. \\ luciano.vasapollo@uniroma1.it
}

Fecha de Recepción: 4 Febrero 2018 Fecha de Admisión: 10 Abril 2018

\section{RESUMEN}

En la situación actual, asistimos a la condición descrita por Gramsci: la saturación de los mercados nacionales ha decidido el fin de los capitalismos y de las burguesías nacionales. El nuevo capitalismo, de mayor contenido innovador, no nace de su encadenamiento a las posiciones de renta presentes en el viejo modelo de producción todavía excesivamente ligado a la producción fordista, deslocalizada hacia áreas en las que hay salarios más bajo y menos legislación laboral. En la fase actual de profundo reacomodo de las fuerzas productivas, es fundamental identificar un instrumento que pueda darnos una medida de la innovación y del curso del progreso tecnológico; creo que el mejor instrumento desde este punto de vista son las patentes, que permiten tanto analizar la fase como la búsqueda de indicaciones sobre el futuro próximo. En la actualización de la teoría del imperialismo las patentes desenvuelven un papel fundamental, porque ofrecen una medida de la diversificación de la última fuerza productiva y, más en general, de aquello que son las relaciones entre ciencia y su aplicación a la producción.

Cierto, el mundo no termina aquí en el nuestro mundo capitalista. La idea tambien de la teoria ocidentalcentrica de la democrazia economica de que la ruptura revolucionaria deba o pueda llegar a los puntos más altos del desarrollo capitalista es un error. Construir de forma independiente las propias perspectivas moviéndose de inmediato en la total autonomía de cualquier modelo consociativo, concertativo y de co-gestión de la crisis. Solamente de esta manera podremos continuar moviéndonos a pasos decididos hacia la democracia economica popular y hasta el Socialismo posible del siglo XXI, como está sucediendo en los países del ALBA. El nuevo hombre martiano y guevariano debe empezar por nosotros, porqué nuestras relaciones personales de una nueva planificacion socio-economica participativa.

Palabras clave: gramsci; progreso tecnológico; planification partecipativa 


\section{ABSTRACT \\ Systemic crisis, "technological" problem and the subsiguent subdesarrollo in the sphere of the production as to that of the circulation.}

In the current situation, we are witnessing the condition described by Gramsci: the saturation of national markets has decided the end of capitalisms and national bourgeoisies. The new capitalism, of greater innovative content, does not come from its link to the income positions present in the old model of production still excessively linked to Fordist production, relocated to areas where there are lower wages and less labor legislation. In the current phase of a profound readjustment of the productive forces, it is essential to identify an instrument that can give us a measure of innovation and the course of technological progress; I think that the best instrument from this point of view are patents, which allow us to analyze both the phase and the search for indications about the near future. In the updating of the theory of imperialism, patents develop a fundamental role, because they offer a measure of the diversification of the last productive force and, more generally, of what are the relations between science and its application to production. True, the world does not end here in our capitalist world. The idea also of the occidental-centric theory of the economic democracy that the revolutionary rupture must or can reach the highest points of capitalist development is an error. Independently build their own perspectives moving immediately in the total autonomy of any consociative, concert and co-management model of the crisis. Only in this way can we continue moving decisively towards popular economic democracy and the possible Socialism of the 21 st century, as is happening in the ALBA countries.

The new martiian and guevarian man must start with us, because our personal relations of a new participatory socio-economic planning.

Keywords: gramsci; technology progress; collaborative planning

1. En la actual situación de crisis sistémica, los economistas mainstream viven una situación de increíble confusión, totalmente incapaces de explicar qué ha sucedido y cuáles son las perspectivas de las economías capitalistas desarrolladas a corto plazo, en el futuro inmediato. Del otro lado de la barricada, Ios intelectuales militantes y quien quiera que luche por la superación del modo de producción capitalista, necesita actualizar los viejos instrumentos de análisis y construir nuevos, con el objetivo de hacer una lectura más convincente de la fase en curso y construir, al modo de Gramsci, "fuerza y consenso" en torno a la propria subjetividad política.

El progreso tecnológico ha alcanzado hoy un nivel tal que gran parte de la producción, especialmente en el campo de las tareas más rutinarias, puede ser sustituida por "máquinas" (entendemos por tales tanto las máquinas clásicas de la sociedad fordista como los más modernos software y productos informáticos). En muchos ambientes intelectuales, también mainstream, gana espacio y se afirma la idea del "mundo sin trabajo". Algunos la ven como una bendición, otros como un maleficio a evitar; Keynes creía que el progreso tecnológico ayudaría a reducir la fatiga y la servidumbre del hombre al trabajo, resolviendo "el problema de escasez que ha sufrido la humanidad encadenada a una pesada vida de fatigas".

Desde la última mitad del siglo XX a nuestro días, la sociedad capitalista ha impuesto una nueva forma de explotación del trabajo: el precariado, problema que se une a la ya citada cuestión del desempleo. Hoy, el problema del trabajo no es solamente una preocupación para quien lo tiene, sino que se extiende a todas las formas del trabajo: eltrabajo incierto, el trabajo negado y el no-trabajo. La idea que tenía Marx del "proletario" hay que volver a analizarla y actualizarla, incluyendo estas nuevas categorías. El desafío es fundamental para los intelectuales militantes de todo el mundo; y 
en línea con la idea de la praxis gramsciana, tenemos que realizar este esfuerzo teórico para ofrecer nuevos instrumentos de análisis a la clase trabajadora y a todas las fuerzas sindicales y políticas que la defienden. En el debate interno, a menudo asistimos a la ficticia contraposición entre "seguros" y "precarios", "jóvenes" y "veteranos", entre otras. Que los capitalistas quieren dividir a la clase es un hecho notorio; pero a nosotros nos toca ver la manera de desenmascararlos, luchando por hacer y mantener la unidad de la clase explotada contra los intereses de los productores de los medios de producción.

De ninguna manera. La "Revoluciones Científico Técnicas", tal y como fueron definidas en el pasado por los intelectuales del bloque soviético, son necesarias, connaturales al propio progreso del desarrollo capitalista y, en consecuencias, a su superación.

Las intuiciones de Keynes eran justas, sin ningún tipo de duda, pero no tenían en cuenta un aspecto fundamental: el problema de la propiedad de los medios de producción y las relaciones de dependencia y de dominio imperialista entre áreas de desarrollo desigual. Sería decididamente naïf elogiar las increíbles ventajas del progreso tecnológico sin considerar el problema de la propiedad del conocimiento, de las patentes y de las máquinas que con todo esto se producen. En otras palabras, los cambios tecnológicos por sí mismos no modifican las relaciones de propiedad ni, por tanto, las relaciones que caracterizan a una sociedad.

2. La cuestión central no es el progreso tecnológico, sino la manera de usarlo para sustituir con capital la "problemática" mercancía viva, o sea los trabajadores (que no aceptan reducciones salariales, hacen huelgas y contraponen sus intereses a los de los propietarios de los medios de producción). Junto con el problema de la propiedad de los medios de producción, las dinámicas imperialistas, de hecho, no permiten que los pueblos de las áreas sometidas a dominio alcancen un desarrollo autodeterminado ni que gocen de las innegables ventajas del desarrollo tecnológico, o porque la tecnología está totalmente ausente o porque estas ventajas no llegan a toda la colectividad.

El problema "tecnológico" y del subsiguiente subdesarrollo afecta, igualmente, tanto a la esfera de la producción como a la de la circulación. En la esfera de la circulación, la dependencia nace del intercambio desigual: productos de alta composición orgánica de capital producidos en los Países desarrollados son intercambiados por productos de baja composición de trabajo y baja especialización provenientes de los Países subdesarrollados.

Un ejemplo evidente de intercambio desigual nos lo da la historia reciente de Oriente Medio; en esta área los monopolios extractivistas occidentales -en particular en el sector petrolero- están efectivamente interesados en frenar el desarrollo de los países dependientes, puesto que éstos exigirían el uso de las mismas materias primas necesarias para la industria naciente. Políticamente, esta situación se ha traducido en un apoyo de los monopolios occidentales a las formas de gobierno más reaccionarias y totalitarias. Solamente estas pequeñas franjas de población local tienen un trato beneficioso de un progreso tecnológico que ha permanecido ligado doblemente a las técnicas extractivas, no aportando ningún beneficio y, al tiempo, desestabilizando y empobreciendo a poblaciones enteras.

En las economías occidentales, el factor conocimiento tiene un papel cada vez más importante dentro del cuadro capitalista, especialmente en las economías occidentales; atravesando cultura, geografía y clases y extendiendo el dominio social más allá de la esfera de la producción.

Frente a tales modificaciones, ninguna de las teorías económicas, desde las clásicas a las neoclásicas y las keynesianas, ha conseguido adaptarse a las dinámicas del desarrollo en la producción del conocimiento.

Incluso en la teoría del valor-trabajo marxista hay un retardo sustancial a la hora de explicar de modo convincente el papel y significado del conocimiento en la creación de valor. Sin embargo, en 


\section{CRISIS SISTÉMICA, PROBLEMA "TECNOLÓGICO" Y DEL SUBSIGUIENTE SUBDESARROLLO EN LA ESFERA DE LA PRODUCCIÓN COMO A LA DE LA CIRCULACIÓN}

un primer análisis, podemos considerar que el trabajo abstracto -el así llamado "cognitariado" - es siempre trabajo asalariado, caracterizado del mismo modo que el trabajo del obrero fordista de los mecanismos de extracción de plusvalía y plustrabajo. El trabajo abstracto es, como cualquier otro trabajo, un determinante del valor de la mercancía, indistinto e indiferenciado. Desde este punto de vista, el conocimiento es clasificable como trabajo complejo o, en palabras de Marx, como trabajo simple potenciado que se incluye en el proceso de producción con un elevado grado de productividad y, por tanto, de competitividad.

3. Los años que han precedido a la crisis hasta nuestros días se han caracterizado por una enorme reorganización de las fuerzas productivas que exigen una actualización y una revisión de los esquemas de análisis, in primis de la teoría marxista del imperialismo. Ya Marx había identificado en el monopolio y en el carácter internacional del régimen capitalista dos de las características fundamentales -y al mismo tiempo de las contradicciones- de este modo de producción. Contrariamente a cuanto ha defendido la teoría económica dominante, el monopolio en el análisis marxista no es la antítesis de la competencia, sino solamente una de sus declinaciones, una fase necesaria en el proceso de acumulación.

Como se puede ver, la teoría marxista del imperialismo debe gran parte de su desarrollo a Lenin, que, partiendo de la investigación marxiana de los rasgos económicos fundamentales del capitalismo, describió las relaciones entre imperialismo o fase monopolista y modo de producción en los Cuadernos Filosóficos, en Materialismo y Empirocriticismo y en El imperialismo, Fase superior del capitalismo. Un aspecto del análisis de Lenin que resulta hoy esencial para la actualización de la teoría del imperialismo es el análisis de los "niveles" o "grados" de la esencia explotadora del capitalismo en su nuevo período histórico de desarrollo.

El fin de la dirección unipolar estadounidense abre la así llamada era de los imperialismos, una nueva fase del desarrollo capitalista caracterizada por la emergencia de más bloques y acompañada por el afirmarse de diversos competidores internacionales. La neo-globalización iniciada en los años 1970 nos ha llevado a una situación en que las riendas del carro no están ya en las manos de las burguesías de un Estado nacional, como en el siglo pasado, sino de la burguesía transnacional, hegemónica en virtud del nuevo impulso propulsor de la internacionalización de los procesos productivos y, en general, de la acumulación del capital. La fase actual del imperialismo no se caracteriza solamente por la agresividad militar, sino que hunde sus raíces en el desarrollo mismo de las relaciones económicas, sociales, políticas e institucionales del modo de producción capitalista; son exactamente estas relaciones las que han generado las inevitables dinámicas de crisis que exigen, consiguientemente, la destrucción del "viejo" capital en exceso y su sustitución por nuevas fuerzas productivas.

De acuerdo con el análisis leninista, la nueva fase imperialista se caracteriza por la emergencia de un nuevo "nivel" en el que no se calman las contradicciones del desarrollo capitalista, sino que, al contrario, se exacerban. El nuevo "nivel" imperialista exige un mayor desarrollo de las fuerzas productivas; al mismo tiempo, los capitalismos se contradicen ellos mismos, al no generalizar este mayor desarrollo. La diferenciación en los grados de acumulación capitalista se eleva así a condición necesaria y, al mismo tiempo, demoledora contradicción en el desarrollo capitalista dentrode las nuevas dinámicas imperialistas. El proceso universalmente conocido como globalización viene así a coincidir con una más amplia reorganización productiva, confirmando las leyes fundamentales de la teoría marxista, desde la ley de la caída tendencial de la tasa de beneficio hasta la ley del desarrollo desigual.

Un segundo aspecto de la nueva fase está estrechamente ligado al funcionamiento mismo del modo de producción capitalista, hablo del carácter cíclico de la producción. La actualización de la 
teoría del imperialismo debe partir de un análisis más detallado de la circulación del capital, con el estudio del ciclo. La liberalización salvaje de los movimientos de los capitales que han caracterizado la afirmación del modelo neoliberal ha acelerado de hecho el proceso de internacionalización del ciclo del capital, decuplicando al mismo tiempo la cantidad de actividad financiera entre los mercados internacionales. El proceso de concentración y de centralización del dinero y de la producción se extiende así más allá de las fronteras nacionales, confirmando la concentración cada vez mayor de la riqueza y el poder político-económico junto con el avance del predominio de los monopolios.

El imperialismo crea las condiciones objetivas para la superación del modo de producción capitalista. Creo que en la actual crisis sistémica se van delineando muchas de las características que Lenin atribuía al "capitalismo agonizante", roto por la intrínseca y contradictoria tensión del monopolio. Como está claro, no se dan en la clase las condiciones subjetivas para la definitiva superación post-capitalista; y esto, además, por un retardo teórico que exige precisar algunos puntos de la teoría del imperialismo.

En primer lugar, la teoría marxista es hoy una teoría de los imperialismos, desde el momento en que la propia ley del desarrollo desigual ha hecho que se desarrollen no uno sino más polos imperialistas. Los imperialismos actuales se caracterizan no solamente y no tanto por el desarrollo progresivo de concentraciones técnicas, económicas y financieras, sino sobre todo por la concentración territorial. La tendencia al monopolio es hoy tan fuerte que no quedan ya más "colonias exóticas" en las cuales los polos imperialistas puedan imponer los propios modelos de desarrollo. En su "La edad del imperialismo", Harry Magdoff describe el Mundo que se estaba delineando en los años 1970 como un "imperialismo sin colonias"; esto no significa que sea menos importante la relación de explotación colonial, sino solamente que los imperialismos consiguen imponer el control político en vastas áreas por la vía de la implicación indirecta en la vida socio-económica y no más a través de la constricción político-militar.

En particular, la mencionada concentración territorial se caracteriza por la creación de "colonias internas" en el mismo polo imperial. Pensemos en la Unión Europea y el país actualmente hegemónico, Alemania: el modelo renano basado en la exportación manufacturera exige la exostencia de áreas de mercado hacia las cuales exportar los bienes. Las políticas que la economía burguesa define como beggar-thy-neighbour (empobrecer al vecino)no son otra cosa que seguir las lógicas imperialistas, en este caso con el objetivo de valorizar en el mercado interno los bienes producidos por uno de los mayores competidores internacionales.

En un plano estratégico, la que fue única potencia imperialista durante medio 1900 se encuentra ahora ante la necesidad de renegociar acuerdos con los BRICS y con la Venezuela bolivariana, como con Mexico y Cubapaíses éstos también debilitados por la caída del precio del barril. Los Estados Unidos, aunque encontrándose en una situación de fuerza relativa respecto a Países golpeados duramente por la guerra económica como Venezuela y Rusia, se ven a sí mismo sometidos a la amenaza del tercer polo en constitución en el Golfo, cuya maniobra ha provocado y sigue provocando la quiebra de centenares de empresas extractivas americanas. El "vals de los intereses" político-económicos ha contribuido de manera determinante a la reactivación del polvorín de Oriente Medio, en una situación en la que las alianzas y posiciones estratégicas cambian continuamente, de acuerdo con las dinámicas en continua evolución al tiempo que de difícil lectura. Se llega así al absurdo de que la Turquía de Erdogan, pieza clave en el actual tablero internacional y exenclave de la OTAN, puede obligar tanto al acuerdo con el gobierno sionista de Israel como a dar apoyo logístico al fundamentalismo islámico y sus financiadores sauditas.

4. El inmovilismo táctico que caracterizó a los años que inmediatamente siguieron a la explosión de la crisis en el 2008 ha llegado ya a su fin, abriendo espacio para conflictos más o menos 
enmascarados y para guerras imperialistas no siempre enfrentadas de manera simétrica. Es difícil predecir hoy cuáles serán los capitalismos de mañana; sin duda, el aumento de las tensiones vistas en los últimos meses (desde Ucrania a Siria y a Turquía) hay que leerlo con los instrumentos propios de la teoría del imperialismo, analizando los aspectos políticos y económicos que subyacen en el actual conflicto entre polos ya afirmado (como los Estados Unidos y la Unión Europea) 0 en vía de constitución (como los seis Países del Golfo). La lucha por el aprovisionamiento de petróleo es sin duda fundamental, pero no la única: el enfrentamiento se sitúa en un plano más general de necesidades energéticas tout court, tocando aspectos más amplios relacionados con la superación del modelo de producción postfordista y la reactivación del ciclo de acumulación.

En este sentido, ¿qué papel juega en el actual tablero internacional la así llamada green economy? ¿Cuánto podrá influir en el futuro la lucha por la hegemonía de las energías renovables en los conflictos interimperialistas?

Como he defendido muchas veces, no tenemos que dejarnos engañar por la terminología y la retórica del "green". La economía verde no es nada más que un modo como otros para hacer negocios, explotando los recursos energéticos cuya propiedad tendría que estar en manos de la colectividad y no en la de poquísimas corporations. Dicho esto, es probablemente a través de la green economy la manera en que los capitalismos contemporáneos buscan la reactivación del proceso de acumulación, intentando salir del actual impasse causado por la continua caída del precio del petróleo.

Es sabido que todo modelo de producción está históricamente caracterizado por diferentes fuentes de energía: así como las primeras formas del capitalismo industrial fueron posibles por el uso del carbón, la producción en los próximos años se basará muy probablemente en fuentes de energía diferentes del petróleo, probablemente más "limpias", pero seguro más convenientes en términos de valorización capitalista. Las fuentes energéticas green son innumerables: pensemos en la eólica, la solar, la geotérmica, la hidroeléctrica, las biomasas, hasta la energía de hidrógeno. En este momento, Arabia Saudita parece haber "apostado" mucho en la energía solar; de cualquier modo, lo que esto revela no es tanto la fuente de energía escogida para la transición postpetrolera como la voluntad de hacerse hegemónica respecto a los otros competidores globales en la competencia sobre las fuentes energéticas tout court. Sobre la decisión de invertir en renovables ha pesado sin ningún tipo de dudas el fuerte aumento de la demanda interna de energía en Arabia Saudita; estoy convencido de que las razones profundas de la inversión hay que buscarlas en el mercantilismo energético árabe, en un contexto en que el nuevo polo imperialista tiene como objetivo estratégico ganar la hegemonía en la producción global de energía.

Las lógicas imperialistas propias de la situación actual no se paran solamente en los procesos de deslocalización, externalización y reorganización productiva hacia las colonias internas y las áreas de menor explotación capitalista. Como último intento de sobrevivencia a la crisis sistémica, las empresas explotan la enorme masa de trabajo inmigrada proveniente de aquellas zonas que hace tiempo se conocían como las "periferias del Imperio". Su ocupación dentro de los polos imperialistas, en el centro de las cadenas productivas permite crear la desigualdad entre clases y dentro de la propia clase que es el presupuesto de la acumulación capitalista. La reorganización de las fuerzas productivas se expresa finalmente en el empleo de trabajadores inmigrantes con salarios más bajos, una vez acabada el recorte del salario de los competidores autóctonos, que permite un aumento de la tasa de explotación y de la tasa de beneficio.

Al mismo tiempo, los capitales transnacionales exigen en una medida creciente un número cada vez más elevado de fuerza de trabajo inmigrada y al mismo tiempo especializada. 14 El desarrollo capitalista en estos siglos nos deja un mundo donde la producción está extremando los límites de sostenibilidad ambiental. Vastas áreas del planeta están irremediablemente contaminadas, la pro- 
ducción industrial amenaza con producir un aumento de la temperatura terrestre del orden de entre 1 y 2 grados, las fuentes fósiles amenazan con comprometer la atmósfera.

5. ¿Por qué es importante que las fuerzas de clase hagan suya la lucha ecologista, no relegándola a mera batalla de las multinacionales y trsnacionales de la green economy? ¿Tiene sentido hablar de ecosocialismo?

Esta pregunta, porque permite recordar a mi hermano Domenico, a poco más de dos años de su muerte; "Mimmetto" dedicó su vida a la causa del medio ambiente, escribiendo textos como "Capitalismo, naturaleza y ambiente" que han enseñado mucho a los compañeros y a los intelectuales militantes, incluyéndome a mí mismo.

En primer lugar, querría empezar por un asunto de base: el mundo de producción capitalista opera en una constante contradicción que no es solamente entre Capital y Trabajo, sino también entre Capital y Naturaleza. Lo que Engels defendía hace un siglo y medio en su "Dialéctica de la Naturaleza" se ha visto confirmado y sigue siendo confirmado por el desarrollo capitalista que, aún pasando por diferentes modelos de desarrollo, trabaja siempre en una continua valorización que ignora i, peor todavía, mina la relación entre Hombre y Naturaleza.

Además, no sólo Engels, también Marx había encuadrado el problema de la sostenibilidad medioambiental en sus escritos. En los "Manuscritos económico-filosóficos de 1844" Marx describió bien la condición humana como la de un "ser natural". En otras palabras, antes de existir en la sociedad (y en particular en la sociedad de clases), el hombre es esencialmente un ser que vive en la Naturaleza, de la cual recibe pasivamente impulsos y condicionamientos; fuera de ésta, el Hombre deja de existir. En el plano económico y de las relaciones entre desarrollo capitalista, clase y Naturaleza, Marx dibuja en el Libro I del Capital el doble conflicto, entre Capital-Trabajo y, en su interior, entre Capital y Medio Ambiente.

Es hoy evidente que la supervivencia biológica de la especie humana está estrechamente relacionada con la supervivencia social; reconocerlo quiere decir en primer lugar comenzar a partir de la base de que es necesario un crecimiento equilibrado e igual dentro de la sociedad. Esto,obviamente, no es posible dentro del modo del producción capitalista; la nueva sensibilidad sobre los temas medioambientales, desde una posición de clase, exige el cuestionamiento de la posición que la economía burguesa tiene en la vida cotidiana, mirando hacia la superación estratégica del modo de producción capitalista.

Desde hace tiempo, asistimos también, en áreas políticas que nos son vecinas, a la apología del crecimiento cero y del fin del desarrollo. Aquellas teorías y formas de ver, que no tenían ninguna relación con las reivindicaciones de clase, han acabado de hecho por justificar la green economy, 0 sea un modelo productivo basado en la puesta en valor de los recursos naturales y, en particular, las fuentes renovables. Pero la explotación de los recursos energéticos - del tipo que sea- no dice nada sobre las dinámicas de explotación del hombre por el hombre. Piénsese en el caso de los Países árabes donde, incluso sin proletariado industrial, podemos observar una distribución de las riquezas y de los réditos extremamente desigual (véase que el índice Gini en Arabia Saudita, según las estimaciones, está próximo al 0.5). No tenemos elementos para poder sostener que la inversión en renovables de la que hemos hablado pueda tener efectos significativos en la mejora de las condiciones de distribución de renta de la población árabe, que podrían incluso empeorar como consecuencia del progresivo drenaje de riqueza necesaria para la financiación de la nueva construcción imperialista.

6. Desde el punto de vista de la sociedad, la internacionalización capitalista provoca una aceleración de la polarización de clases: cada vez menos capitalistas poseen cada vez más riqueza relativa respecto al número creciente de proletarios, tanto en las economías del así llamado "Centro", 


\section{CRISIS SISTÉMICA, PROBLEMA "TECNOLÓGICO" Y DEL SUBSIGUIENTE SUBDESARROLLO EN LA ESFERA DE LA PRODUCCIÓN COMO A LA DE LA CIRCULACIÓN}

como en las de la "Periferia". Al mismo tiempo, aunque dentro de la homogeneidad de clase, emergen cada vez más diferencias económicas; en particular, contradicciones que se agudizan en el seno de la misma burguesía, con el alejamiento progresivo entre la oligarquía financiera y el resto de la clase burguesa. Tales dinámicas producen, obviamente, importantes repercusiones políticas, que llevan a una intensificación de la lucha por la supervivencia del régimen de producción y del sistema social como tal en una escala plenamente internacional. Entrando más a fondo en la realidad, es sin embargo esta plena internacionalización la que ha marcado el declive de la guía unipolar estadounidense; un imperio que ha entrado en crisis exactamente por la incompatibilidad con algunas de las dinámicas de la expansión internacional.

La primera contradicción se da entre el imperio USA en expansión y la "república" en declive, con la consiguiente dificultad para transferir riqueza, réditos y fuerza de trabajo para la construcción imperial, en un cuadro de declive social generalizado, con el fin de la así llamada american way. La segunda y más grave contradicción se da entre el imperio militar en expansión y la incapacidad de extraer beneficios de las regiones recientemente colonizadas, a pesar de los beneficios provenientes del petróleo. A partir de la Guerra del Golfo y en particular con la llegada al mercado de los petrodólares surgido en Oriente Medio los intereses de las oligarquías locales, oponiéndose a los estadounidenses, han generado verdaderos conflictos interimperialistas.

A un nivel mucho más general, podemos afirmar que la saturación de los mercados nacionales ha exigido una nueva fase de mundialización de la economía capitalista en sentido imperialista. La nueva economía tiene la constante y continúa necesidad de valorizar la cadena de capital; esto a la larga no puede producir más que crisis y conflictos interimperialistas. Los años recientes nos hablan de una paz momentánea, pero principalmente de guerras militares y guerras económicas que se multiplican por doquier, especialmente en las periferias de los polos imperiales. Todos estos elementos constituyen piedras angulares del modelo neoliberal, pero creo que la victoria de este proyecto político y económico asienta las raíces en la capacidad de garantizar una estabilidad económica (¡no solamente social!) del Centro, a pesar y, más todavía, gracias a la inestabilidad en la Periferia. La estabilidad económica opera sin embargo contra la estabilidad social y la autonomía de los pueblos, sometidos al totalitarismo de la competición global entre bloques geoeconómicos.

Querría recordar a un grande maestro, Alessandro Mazzone, que hace ya treinta años ponía en guardia a los marxistas en relación a la creencia de "afirmaciones singulares" de acuerdo con las cuales "las cuestiones globales o 'cuestiones del género humano' serían indiferentes a las clases 0 que incluso transcenderían las cuestiones de clase.» Creo que esta advertencia es hoy más actual que nunca para evitar que la defensa de un "mundo sostenible" sea tal que deje de lado las reivindicaciones del conflicto de clase 0 , con palabras de Mazzone, "Ios contrastes en los que hasta ahora se ha desarrollado la historia de los hombres".

En el contexto capitalista de desarrollo desigual hay que recordar finalmente que son los países así llamados "desarrollados" o "avanzados" los principales responsables de los efectos devastadores de su modo de producción, que funciona con lógicas coloniales e imperialistas. Hoy, quien principalmente reivindica el "derecho a contaminar" son los BRICS, así como todos aquellos países como el Mexico,que aspiran a convertirse en competidores globales en la manufactura y la producción de base fordista. El peso que esta situación carga sobre el medio ambiente tiene efectos políticos distorsionadores en relación con las necesidades reales y el derecho a la autodeterminación de los así llamados países en vías de desarrollo al perseguir sus caminos de emancipación social y económica.

7. Gramsci defendía que "la crisis consiste en el hecho de que lo viejo muere y lo nuevo no puede nacer". Al analizar los conflictos interimperialistas y su evolución histórica, también para 
hacer una lectura convincente de la fase, es necesario mirar no solamente al viejo capital, sino también al nuevo, al capital de más alto contenido innovador.

La reaparición de conflictos, a menudo a pocos pasos de la "Fortaleza Europa", así como el terrorismo dentro de las fronteras, ha revitalizado la discusión en torno a la dicontomía keynesianismo militar-keynesianismo social. Muchos economistas, especialmente entre los keynesianos "de izquierda", se sorprenden ante los intentos de recuperación del crecimiento económico a través del armamento antes que recorriendo al keynesianismo social, mediante políticas de apoyo a las rentas que puedan relanzar el consumo.

En las crisis, el keynesianismo militar viene al encuentro de las exigencias del modo de producción por dos tipos de motivos: de un lado, la necesidad de mantener el desarrollo desigual; y del otro, la exigencia de planificación capitalista.

En relación al primer aspecto, el recurso a políticas de expansión del gasto militar encuentra justificación en el mantenimiento de las relaciones de fuerza tanto dentro como fuera del polo imperialista. Por una parte, está claro que la fuerza o la amenaza de su uso pueden "desanimar" a los países competidores y a los otros bloques imperialistas dominantes, haciendo que se mantengan intactas y, más todavía, que se perpetren las dinámicas implícitas a la ley del desarrollo desigual. Desde otro punto de vista, dedicar recursos de las medidas sociales para las de tipo bélico-militar ayuda a mantener dentro del polo imperialista una situación de creciente desigualdad. En años recientes se ha hablado mucho de la desigualdad como "enfermedad" del capitalismo contemporáneo. No hay duda de que para un marxista una posición como ésta no puede más que aparecer como una clara mistificación de las dinámicas históricas; la desigualdad no es una consecuencia, sino que constituye, muy por el contrario, la premisa de los criterios de acumulación del capital. El keynesianismo militar, a través del mantenimiento de la demanda pública del aparato y el complejo industrial militar, ayuda a mantener dentro del polo imperialista situaciones de dependencia y explotación funcionales a la propia acumulación del capital.

Por lo que hace al segundo aspecto, el keynesianismo militar desenvuelve la tarea fundamental de planificación de las dinámicas de acumulación en un contexto en que la industria y el mercado no son capaces de garantizar una adecuada productividad del capital, aunque en lugar de una mayor explotación de los trabajadores asalariados. La intervención pública, de manera totalmente conforme a la visión keynesiana, es funcional a la corrección de las extravagancias, de los errores y de las ineficiencias que tienen lugar en el mercado cuando intenta la valorización de los bienes en una condición de fuerte caída de la tasa de beneficio.

En la expansión del gasto para fines bélicos podemos ver además un gran paralelismo entre neoliberalismo y keynesianismo privatizado". También después del viraje neoliberal, de hecho, se puede confirmar que los intereses geoeconómicos del capital juegan un papel fundamental en la definición de las formas de relación social, tanto en el Centro como en la Periferia.

Las actuales lógicas imperialistas han llevado a la organización de la producción hacia ciclos cada vez más complejos e internacionalizados. ¿qué incidencia tienen en el análisis marxiano las cadenas productivas, los distritos industriales y las tantas otras formas de organización de la producción?

Recordamos cómo se explica la contradicción marxiana entre desarrollo de las fuerzas productivas y relaciones de producción. Por fuerzas productivas, Marx entiende los individuos que trabajan y constituyen la fuerza-trabajo, los medios de producción y el conocimiento técnico y científico. Las relaciones de producción se establecen en la esfera de la producción, como el conjunto de las relaciones que constituyen "la estructura económica de la sociedad, o sea la base real sobre la cual se eleva una superestructura jurídica y política a la que corresponden formas determinadas de la conciencia social". 
8. El desarrollo de nuevas formas de organización de la producción responde concretamente a esta necesidad de "retirar el obstáculo" que las relaciones de producción constituyen para el desarrollo de las fuerzas productivas. De tal modo, en los últimos veinticinco años hemos asistido a la difusión de las cadenas productivas de carácter internacional, o sea de una serie de operaciones de transformación que permiten la producción de bienes y productos de maneras diferentes respecto a la época fordista-taylorista, incentivando a los sectores más vinculados de la competición global y a un mayor contenido de valor. La cadena se identifica como ciclo de carácter productivo de tipo espacio-temporal que, desde una óptica internacional, consigue valorizarse en los contextos donde más débiles son las contradicciones entre Capital y Trabajo. Las empresas tienden a asumir una estructura integrada tanto en el campo de la producción como en el de los capitales: la así llamada "globalización financiera" inciden de esta manera sobre la vieja estructura orgánica de la empresa, abriendo paso a la externalización de varias funciones y fases del completo proceso de trabajo, delegadas a sujetos jurídicamente autónomos, pero económicamente dependientes y controlados por la empresa. La cadena tiene, por otro lado, el papel de recoger los capitales más pequeños, a través de una centralización tendiente al monopolio que responde a una lógica plenamente imperialista. Gracias a la cadena, la empresa madre consigue explotar las relaciones de fuerza entre los varios capitales, absorbiendo por otro lado parte del salario creado a lo largo de la cadena y aumentando así la extracción de plusvalía.

Es por tanto nuestra obligación actualizar aquellas intuiciones, mediante la construcción de la teoría de la economía socio-ecológica-política que ponga en el centro las compatibilidades sociales y medioambientales, en favor de un profundo cambio inmediato, hacia el horizonte de un socialismo que no solamente es posible sino que es, en definitiva, necesario.

Solamente poniendo en el centro la dimensión de clase y encuadrando el conflicto CapitalNaturaleza dentro del conflicto Capital-Trabajo podemos construir una visión y una teoría plenamente ecologista y anticapitalista.

La Naturaleza no es una entidad neutral; su defensa exige un análisis que tenga en cuenta las dinámicas de clase y que mire a la resolución del conflicto por la vía de la superación de este modo de producción, en favor de un progreso sostenible porque autodeterminado.

La existencia de un conflicto irresoluble entre Capital y Naturaleza empieza a aparecer claro también para los sociólogos y economistas no marxistas. Pero sostener que la solución pasa únicamente por la superación del modo de producción podría dejar a las fuerzas ecologistas sin instrumentos en la lucha de oposición a los desastres ambientales que cada día se realizan en la carrera famélica por la valorización de los productos.

Limitarse a describir una situación futura hacia la cual nos dirigiríamos podría llevar a una minusvaloración de la barbarie contemporánea: hay que poner un límite inmediato a los estragos que las multinacionales y otras corporations están llevando a término cada día contra el medio ambiente; 0, de otra manera, parafraseando a Fidel Castro, no podremos ver un mañana el socialismo realizado en todo el Mundo.

Hay que elaborar un programa para esta fase, bien definido, como tentamos en en libro.

Los deseos y necesidades de un sector de las y los ahorradores no se pueden lograr con el sistema financiero tradicional.

La finanzas ética por ejemplo busca la transformación de la sociedad y argumenta que que esto pasa por potenciar otra educación, poner el arte y la cultura al alcance de todo el mundo, promover la salud de manera integral, pensar iniciativas de crecimiento personal para realizar el fortalecimiento de la economía solidaria.

Ofrecer financiación a familias que se organizan en cooperativas participativas y invertir en 
comercio justo es pensar a un modelo que garantiza recibir un precio justo por el trabajo realizado y beneficios para la comunidad.

La finanzas éticas no quiere rechazar las reglas fundamentales de las finanzas tradicionales, pero quiere reformar los valores sobre los cuales se fundan las finanzas sobre las compatibilidades socio-ambientales, realizando batallas a contramano impulsadas por los movimientos y sindicatos que consigan finalmente rechazar la ficticia contraposición entre las cuestiones medioambientales y las retributivas.

9. En la situación actual, asistimos a la condición descrita por Gramsci: la saturación de los mercados nacionales ha decidido el fin de los capitalismos y de las burguesías nacionales. El nuevo capitalismo, de mayor contenido innovador, no nace de su encadenamiento a las posiciones de renta presentes en el viejo modelo de producción todavía excesivamente ligado a la producción fordista, deslocalizada hacia áreas en las que hay salarios más bajo y menos legislación laboral. En la fase actual de profundo reacomodo de las fuerzas productivas, es fundamental identificar un instrumento que pueda darnos una medida de la innovación y del curso del progreso tecnológico; creo que el mejor instrumento desde este punto de vista son las patentes, que permiten tanto analizar la fase como la búsqueda de indicaciones sobre el futuro próximo. En las economías modernas, las patentes representan una nueva forma de propiedad privada inmaterial de los medios de producción; el título que confiere la patente da derecho a las rentas financieras que son un presupuesto de la acumulación capitalista y de su tendencia al monopolio. Las patentes constituyen un instrumento potentísimo de "garantía jurídica" de las posiciones monopolistas y oligopólicas; la posesión de una patente implica la capacidad de dominar e incorporar a la inteligencia social en la producción capitalista.

En la guerra de patentes se esconden los mecanismos más despiadados de los conflictos interimperialistas y de la lucha entre capitales; la garantía de la propiedad intelectual acaba cada vez más a menudo coincidiendo con una actividad salvaje de apropiación de bienes inmateriales por parte del capital privado.

En la actualización de la teoría del imperialismo las patentes desenvuelven un papel fundamental, porque ofrecen una medida de la diversificación de la última fuerza productiva y, más en general, de aquello que son las relaciones entre ciencia y su aplicación a la producción. En el actual Profit State, la concentración de enormes y crecientes masas de capital se genera por sí misma: los oligopolios y los monopolios pueden permitirse centros de investigación costosísimos para desarroIlar nueva tecnología, inventar nuevos productos y reforzar sus rentas y posiciones prevalentes en el mercado. El capital menor, no teniendo las fuerzas para competir, sucumbe 0 es absorbido. En conjunto, el bloque del libre acceso al conocimiento comporta una ulterior reducción de la competencia, alargando los tiempos de reparto equitativo de la tasa de beneficio y manteniendo situaciones de privilegio que reducen los estímulos a la producción de nueva tecnología.

En la actual situación de crisis sistémica las patentes dan, además, una medida del desarrollo desigual en el interior de los propios polos imperialistas, determinando una penalización de los polos menos innovadores y caracterizados por una producción todavía basada en los mercados nacionales.

Los datos sobre patentes confirman lo argumentado en el análisis teórico: dentro del polo imperialista europeo, Italia y los PIGS están en los últimos lugares por el número de patentes, registrando una inflexión en los últimos veinte años y en particular en la crisis. Del mismo modo, los BRICS no crean ninguna innovación, o sea que se cualifican plenamente como países en competencia de acuerdo con el modelo de producción peculiarmente fordista. Un dato que nos tiene que hacer pensar viene de los Estados Unidos, donde el número de patentes está muy estancando, lo que es una 


\section{CRISIS SISTÉMICA, PROBLEMA "TECNOLÓGICO" Y DEL SUBSIGUIENTE SUBDESARROLLO EN LA ESFERA DE LA PRODUCCIÓN COMO A LA DE LA CIRCULACIÓN}

medida de la pérdida de hegemonía en el mercado global de la que hasta hace pocos años era la única gran potencia capitalista.

Volviendo a la situación dentro de la Unión Europea, podemos notar como el mayor crecimiento en el número de patentes se encuentra en el este de Europa y en los países bálticos (Estonia, Letonia y Lituania): estos países, de hecho, desempeñan la doble función de ofrecer fuerza de trabajo a bajo precio, pero con una especialización alta, constituyendo sustancialmente el habitat ideal para las patentes. En el actual cuadro, no está todavía claro cuál pueda ser el papel que jugarán las oligarquías árabes, pero la elevada inversión en innovación de los recientes años podría sumar nuevos competidores en la guerra de las patentes.

Globalmente, no es fácil imaginar a dónde nos llevará este proceso, pero una cosa está clara: la tendencia de los capitalismos al monopolio genera crisis y conflictos no sólo entre los capitales de diversos polos imperialista, sino también dentro de los mismos y en relación con las particulares áreas geográfica y contextos institucionales.

10. Cierto, el mundo no termina aquí en el nuestro mundo capitalista. En otras partes del mundo los campesinos y los obreros, que representan más de cuatro quintas partes de la humanidad, el proletariado que vive del propio trabajo o se ven obligados a pasar hambre hasta la muerte por el trabajo negado, son millones que están saliendo progresivamente del estado minoritario y de semiesclavitud en el que han estado durante siglos; toman conciencia de su condición, fortaleciendo y reclamando el vínculo con la tierra, que en muchos casos se convierten en la base para nuevas experiencias de gobierno democrático participativo y protagonico, revolucionario, como en los países de ALBA, economías autodeterminadas donde se actúa para y por el uso social de los bienes, sobre la apropiación popular, proletaria de los bienes comunes, donde como en nuestra ALBA se vive la fase actual del nuestro socialismo. La idea tambien de la teoria ocidentalcentrica de la democrazia economica de que la ruptura revolucionaria deba o pueda llegar a los puntos más altos del desarrollo capitalista es un error. Una herencia de los padres del socialismo que en la historia no se ha dado jamás.¿Debemos tomar conciencia de ello?

Construir de forma independiente las propias perspectivas moviéndose de inmediato en la total autonomía de cualquier modelo consociativo, concertativo y de co-gestión de la crisis.

Sólo así la autonomía del modelo socialista de democracia asume la verdadera connotación de independencia de los diversos modelos de desarrollo consentidos e impuestos por las varias formas de capitalismo, todas ellas expresiones del mismo sistema de explotación impuestas por la única forma de producción capitalista.

Estamos convencidos de que intensificando el proceso de nacionalización de los medios de producción, controlando el sistema bancario y el comercio externo, expropiando todas las empresas que aplican las mil formas de boicot a los procesos revolucionarios, aislando a todos los pseudorevolucionarios que quieren una democracia de estilo eurocéntrico de capitalismo "suave y democrático", solamente así si puede realmente proceder en el devenir histórico para la superación del modo de producción capitalista con formas acertadas y desarrolladas de transición al socialismo contra cualquier ideología de mediación que pueda hacer fracasar toda forma de transición al socialismo.

Así pues, la batalla que hoy estamos llamados a desarrollar los gobiernos revolucionarios y progresistas y los pueblos de Sudamérica es la de plantear inmediatamente sobre el terreno del cambio político la conquista del poder y no aceptar formas de oposición "leal" por parte de las estructuras políticas del capital, ya que mediar con sistemas políticos de la democracia burguesa sin tocar los mecanismo del modo de producción capitalista significa verse condenados al fracaso, como la historia desgraciadamente tanta veces nos ha demostrado ya.

También la gran y exitosa llamada a salir a la calle de las fuerzas revolucionarias chavistas para 
defender la revolución bolivariana, que dejó muy claro que el intento por parte de los mercenarios del imperio y de la oligarquía por crear las condiciones para un golpe, debe ser solamente una fase del camino por el relanzamiento y el reforzamiento de las formas políticas y sociales y económicas de la transición al socialismo.

Concluyendo, son exactamente las modificadas condiciones de explotación del medio ambiente las que nos ponen ante el desafío de construir en la teoría y en la práctica una nueva visión económica, que supere críticamente la economía convencional y se realice como economía socio-ecológica-política. Solamente de esta manera podremos continuar moviéndonos a pasos decididos hacia la democracia economica popular y hasta el Socialismo posible del siglo XXI, como está sucediendo en los países del ALBA. Marx y Engels entendieron, observando las condiciones degradantes de los slums ingleses, los efectos destructores que la producción capitalista tenía para el medio ambiente y para la cualidad de vida de millones de personas; no podían sin embargo imaginar la dimensión que estos efectos podría alcanzar a nivel global.

No debemos esperar por fuerza a que se realize el socialismo "perfecto" para tener entre nosotros relaciones verdaderas y estrechas entre compañeros que buscan construirse, antes de construir, un nuevo hombre de la pasión y del amor revolucionario. El nuevo hombre martiano y guevariano debe empezar por nosotros, porqué nuestras relaciones personales de una nueva planificacion socio-economica participativa, no tenemos que olvidarlo jamás, ya son una forma de vivir el socialismo....jiaquí y ahora!!

\section{BIBLIOGRAFIA ESENCIAL DEL AUTOR}

Vasapollo L., Critica a la economia aplicada convencional, Editorial Felix Varela, La Habana, Vol.1, 2009; Vol.2, 2010, Vol.3., 2010

Vasapollo, L., Trattato di critica dell'economia convenzionale. Vol. 1: La crisi sistemica. Metodi di analisi economica dei problemi dello sviluppo, Jaca Book, 2012.

Vasapollo, L., De Sur a Sur: la estrategia del caracol, Ediciones de Intervención Cultural, 2014.

Vasapollo, L., Martufi, R. e Arriola, J., El despertar de los cerdos PIIGS. Una alternativa geoestratégica y monetaria de los PIIGS, Maia Ediciones, Madrid 2014.

Vasapollo, L., Trattato di critica dell'economia convenzionale. Vol. 2Un sistema che produce crisi, Jaca Book, 2013;

Vasapollo L., Crisis of Capitalism . Compendium of Applied Economics (Global Capitalism), Brill, Leiden-Boston, 2012

Vasapollo L., Tratado de Metodos de Análisis de los sistemas economicos. Mundializacion capitalista y crisis sistemica, Banco central de Venezuela , 2013 
